\title{
Acculturation and Traditional Mortuary Rites of the Nawfia of Southeastern Nigeria
}

\author{
Ugochukwu T. Ugwu \\ http://dx.doi./org/10.4314/ujah.v22i1.1
}

\begin{abstract}
This ethnography explores the traditional mortuary rites of the Nawfia, an Igbo group of Southeast Nigeria, aiming to understand the mortuary rites of the Nawfia, how and why it has changed and the factors responsible for the changes. The main data collection strategy was participant observation that began in April 2014. It was supplemented with in-depth interviews and focus group discussions. The study found Christianity as a major acculturative factor that has altered almost all the facets of the traditional mortuary rites of the Nawfia Igbo. Furthermore, mortuary rites do not only reinforce social solidarity among the Nawfia Igbo people but also according to what the Nawfia people believe, enable the deceased to attain his rightful position in the spirit world.
\end{abstract}

Keywords: traditional mortuary rites, mortuary rites, southeast Nigeria, Igbo people, acculturation

\section{Introduction}

Mortuary rites have been extensively researched across the world, Africa and the Igbo in particular. These studies were initiated by colonial anthropologists, who hurriedly, for purposes of administration, tried to document what they met on ground, and for easier understanding of how mortuary rites reinforce social solidarity or religious efficacy. Among these were sometimes untrained ethnographers that studied these rites from an ethnocentric 
perspective. For instance, without trying to understand these rites relative to the context and the complex Igbo societies, Basden (1983) concluded his account on mortuary protocols as representing the general Igbo funeral rites, albeit, with ethnocentric disgust. Unlike Basden, Talbot (1969), as an academic ethnographer, albeit, colonial anthropologist, conducted his own study among the Ibibio of southern Nigeria. This study generated multi-volume publications that attempted with rigor to provide a holistic ethnography of the region.

Classic anthropological fieldwork emphasized working 'abroad' - that is, doing fieldwork in societies that were culturally and geographically distant from that of the ethnographer. More recent discussions of anthropological fieldwork have drawn attention to the significance of working 'at home' - including paying attention to the forms of social differentiation and marginalization present in the society to which the ethnographer belongs (Shultz, Lavenda\&Dods, 2009). Kottak $(2008,2010)$ has even argued that native anthropologists are better qualified to study issues involving their group than outsiders are. I grew up in Enugu, different from the area of this research. Much have changed in the Igbo's life-ways since the mid-19th centuries when they began to encounter westernization.

After colonialism, there has been a dearth of native ethnography on traditional mortuary rites, in terms of continuity and/or change among various Igbo groups. In this study, a basic research, I deliberately seek to understand the post contact Nawfia Igbo mortuary rites. I explore the acculturative factor(s) that may have affected their mortuary rites. 


\section{Exploring Mortuary Protocol}

According to Borgatta and Borgatta (1992: 413), death is typically viewed as a transition, as a 'rite de passage.' It is a transition from one life to another life. Death is a personal event that man cannot describe for himself. Man has been both intrigued by death and fearful of it. He has been motivated to seek answers to the mystery and solution to his anxiety. Borgatta and Borgatta (1992: 413) noted also that every known culture has provided some answers to the meaning of death, for death, like birth or marriage, is universally regarded as a socially significant event, set off by ritual and supported by institutions. It is the final 'rite de passage' (Riley, 1968). As the final rite of passage, it means that the cycle of life is over. But is this actually the final cycle? What about those who go to heaven or hell according to the doctrines of some religions? What about those who join their ancestors? Noteworthy is that in each of the above, another cycle of life is established with new roles. For me it is a luminal phase for the joining of ancestors where the whole life cycle starts again but in a different reality. Riley (1968), also noted that the meanings which have been attached to death in most cultures include beliefs in some kind of existence after death; most people save the non-literate - have entertained theories of personal salvation, and religion, philosophy, and political ideology have provided some answers to man's quest for the meaning of death.

Death is a universal phenomenon. Yet it evokes incredible varieties of responses. Kottak (2008) recorded that Americans regard expensive weddings as more socially appropriate than lavish funerals. However, the Bestileo of Madagascar take the opposite view. The marriage ceremony is a minor event that brings together just the couple and a few close relatives. A funeral is a measure of the deceased person's social position and lifetime achievements, and it may attract a thousand people (Kottak, 2008). 
Corpses of human persons are either burnt or buried, with or without animals or human sacrifices. They are either preserved by smoking, embalming, ritually exposed as carrions, simply abandoned, or they are dismembered, and treated in a variety of these ways (Huntington \& Metcalf, 1979). Wilford (2004) described the archaeological excavations that proved ancient Egyptian practice burying a deceased pharaoh with a number of companions to serve him in the afterlife. This diversity of cultural reactions in the opinion of Huntington and Metcalf (1979) is a measure of the universal impact of death. But it is not a random reaction; always, it is symbolic, and in a number of cases, expensive.

In the opinion of Talbot (1969) death is just like a dream. Death is a male and dream is a female. The death of one who has not reached old age is more often than not regarded as unnatural and is commonly thought to have been caused by witchcraft or to some juju[1] or medicine. One of the first acts of the bereaved family is to procure the services of a diviner and ask him to find out the cause, with the result that it is often followed by many other deaths.

Among most ethnic groups in Nigeria, the proper carrying out of mortuary rites is the most important duty in life. Families are known to impoverish themselves for years in order to give a befitting burial to an important member (Talbot, 1969). For an old man, there is great need for a proper burial to ensure that he lives well and happy in the spirit world and that he reincarnates into another life without any problem.

Basden in his studies among the Igbo people described the excitement that follows death among the Igbo as follows:

As long as breath remains in the body there is little excitement. Some sit or stand with sorrowful countenances, while others move about in a casual 
manner, seemingly but little affected by the scene. But immediately the patient dies there is a wild outburst of wailing. In the case of a near relative, as a wife for her husband, or a mother for her child, it speedily developed into a form of frenzy. The bereaved woman rushes forth from the death chambers, heating her breast, and runs through the village bewailing her loss at the top of her voice. She salutes none, but continues to cry out even when she has left the town behind her. A woman will thus pass the whole night in the bush pouring out her lamentations, and returns next morning in an utterly exhausted condition (1983:112).

In his own view, Obiechina (1988) stated that the traditional people believed that death was only a transition - a means of passing from the world of man to that of the spirit world. Chukwuelobe (1998) reported that death is very important in Igbo life as it marks new birth and embodies transition to the ancestral spirituality of the Igbo. Menkiti described death as a necessary rite of passage for entry into the folk of Igbo ancestors:

After birth the individual goes through the different rites of incorporation, including those of initiation at puberty time, before becoming a full person in the eyes of the community. And then, of course, there is procreation, old age, death, and entry into the community of departed ancestral spirits--a community viewed as continuous with the community of living men and women, and with which it is conceived as being in constant interaction (Menkiti, n. d.). 
Basden (1983) recorded that burial rites among the Igbo people are governed chiefly by considerations of birth, rank, and the cause of death. A slave receives but scant attention, and no unnecessary expenses will be incurred in carrying out the last rites for him. For a free-born man, the best possible arrangements must be made - there must be no half-measures and no stinginess on the part of the family. In the case of a chief or a wealthy man, the highest honour would be rendered and no expenses spared to give relatives a worthy send-off. On the other hand, the persons who died of leprosy, or of noxious diseases and those whose death cannot be satisfactorily accounted for, are buried hurriedly. Obiechina (1988) recorded also that children, and women who did not take titles were not given elaborate burials.

Basden (1983) noted that people dying as the result of accidents, women dying in childbirth, lunatics, suicide and those who have been murdered, drowned or burned are not rubbed with the ufie which is done in the case of normal death and they must be buried without delay. When the head of a family dies, or a chief, he is buried in a deep grave beneath the floor of his private apartment. This also corroborates Obiechina's account that people who committed suicide of any type are not given any type of burial, whether first or second burial (Obiechina, 1988).

Basden (1983) recorded that on the western side of the river, the death of a king must not be proclaimed until the arrival on the scene of his eldest son, who naturally inherits the throne. The underlying idea is that the throne is never vacant. 'The king is dead; long lives the king' is the maxim that applies in this case.

Death is a transition. But it is only the last in a long chain of transitions. In Hertz's view (1960), the moment of death is related not only to the process of afterlife, but also to the process of living, aging and producing pregnancy. Death relates to life: to the recent 
life of the deceased and to the life he or she has procreated and now left behind. Ikwuemesi and Onwuegbuna have recorded that while mourning, the Igbo celebrate death as a way station to the ancestral life of spirituality (Ikwuemesi \& Onwuegbuna, 2018). Ikwuemesi (2021) noted that death among the Igbo is not the end of life but is seen as an entree road to the otherworld

VanGennep (1960) recounted that of the rites of passage, funerals are most strongly associated with symbols that express the core of life values sacred to the society in question. This rite of passage follows a standardised pattern in different societies. Nwanunobi, Obikeze and Onu (2004) stated that one of the characteristics of culture is that it is dynamic. Dynamic here implies that culture encourages borrowing of traits from another society. There is nothing wrong with a society borrowing ideas or artefacts from another society. However, humanity as a whole might lose if a culture ignores its own traits to become a chronic consumer of the traits from other cultures (Igbo \& Anugwom, 2002:52). Continuing on their opinion, the advent of Christianity, which is an aspect of western culture and belief system and the erosion of the power and influences of traditional religion and beliefs, which it brought was a direct attack on the culture of traditional African societies. Ogbagu has noted the changing nature of meanings attached to death and lavish ceremonies associated with death among the Igbo. This has to do with the show of economic affluence. Also, technological innovation has contributed to this changing funeral rites (Ogbuagu, 1989). This may or may not be true in the case of Nawfia Igbo. In view of the foregoing, this study seeks to ethnographically understand: the mortuary rituals of the Nawfia, how and why it has changed and the role Christianity played in the change process. 


\section{Methods}

\section{Participant Observation}

There are numbers of options in participant observation, depending on the need of the researcher (Bernard, 2006; Okpoko \& Ezeh, 2011; Babbie, 2005). The option that favours objectivity and ethical consideration, participant observer, was the major data collection strategy for this study. The researcher conducted semi-structured interviews and focus group interviews with 15 participants selected purposely across the villages of Nawfia listed below. Also, daily chit-chatting was a useful instrument of data collection.

Every community has people who by accident, experience, talent, or training can provide the most complete or useful information about particular aspects of life. These people are in the words of Okpoko and Ezeh (2011), reliable informants. The researcher conducted in-depth interviews with people known to have special knowledge of the autochthonous mortuary rites of the Nawfia Igbo people. However, getting to these set of people was not easy as the researcher kept interviewing every person who showed interest in a burial setting. If the person had no idea of what the researcher sought, the person would direct the researcher to the persons believed to have some knowledge and the process continued in that direction until saturation point, where I had to make a choice, guided by cultural consensus model (Ember, et al., 2007; Bernard, 2006).

Nawfia, an Igbo group of South-eastern Nigeria formed the area of this study. Nawfia is in Njikoka Local Government Area of Anambra State, Nigeria. Among the sub-communities that make up Nawfia are:

(a) IfiteNawfia (which comprises five villages) and are exogamous. 
(b) Umuriam (which is made up of three villages) and are exogamous.

(c) Mmimi (Enugo and Adagbe) which are endogamous.

(d) Umukwa which is exogamous.

Nawfia lies in the latitude of $6^{0} 11^{\prime} 18 \mathrm{~N}$ and longitude $7^{0}$ 0 '58E. It is bordered to the West by Abagana, UkpoAkpu, etc. and to the North by Enugu Agidi, and Nawgu. In the East lies Umokpu, Amawbia, Nise, etc., and in the South by Nimo, and Enugu-Ukwu.

Nawfia Igbo was chosen for this study because of her traditional characteristics and cultural uniformity. This implies that Nawfia Igbo still maintains parts of her indigenous values and ways of life. As a basic research, this study is not designed to make recommendations or value judgments as are the case with applied research. My intention is to understand the mortuary rites as an institution under continued transformation.

This patrilineal society traces its ancestral origin from Nri. Nri is a well-known area of the Igbo, which performs spiritual functions connected with the coronation of kings and purification rituals when the members of the Nawfia Igbo commit abomination (aru). Ancestral mediated veneration in relation to the divinity is by rule a religious practice here. Ezu River has a spiritual potency for healing and purification. Pre-contact marriage institution favoured polygyny, which was fostered equally by men and women; in some respects, the latter are the chief supporters of the system. Patrilocality is a rule and the Nawfia political structure is uncentralized

The Nawfia mode of subsistence is agriculture. Their staple food is yam, which measures the strength and weakness of men. Palm-wine tapping and hunting are by rule exclusive to men. Women controlled other types of crops and market exchange. 


\section{Focus Group Discussion}

I used Focus Group Discussion (FGD) as a supplement to evaluate the data gathered from participant observation. Okpoko and Ezeh (2011) affirm that there is no set number of persons who may be participants in a study, nor a prescription on the number of FGD sessions that may be done: all depends on the funding and research objectives. Following this, the researcher conducted two group sessions of eight participants each. Each group was made up of four men and four women. The FGD participants were chosen purposefully through personal contacts. These participants were selected from Mmimi, Umukwa, Umuriam and IfiteNawfia. With the help of a research assistant trained for recording, the FGD sections were conducted while the researcher moderated. One FGD section was conducted at Ifite while the other FGD section was conducted at Umukwa.

\section{Analysis}

Data analysis began with the collection of data. Daily field experiences are recorded, sorted for meaning and the researcher coded and grouped the data obtained after each fieldwork to prepare for further field activities. Descriptive coding is seen as suitable for ethnographic studies (Saldana, 2013). Summarily, analysis of data obtained from participant observation started with deducting excerpts from field notes and tapes, categorization of excerpts into common facts and uncommon facts. Next is sorting and analysis of facts based on different objectives of the research, and writing up the report.

In order to examine the validity and reliability of the research findings, and of the researcher's interpretation of them, the researcher consulted those who participated in the research. The cultural consultants acted as judges, evaluating the findings of the 
study. Furthermore, focus group discussion (FGD) sessions were conducted at the end of the data collection to help cross check the validity and reliability of the data collected from other instruments. Because the focus group sessions were conducted via mixed languages, data were transcribed and translated to English. Codes were given to the translations based on similarities and differences. The reports were organized under themes, reflecting the objectives of the study. I compared and contrasted one group session to another, in terms of gender category, and finally aligning the result with that got from other instruments. The report is conducted in a way that allows weaving of the data obtained from all the instruments into the narrative. Nevertheless, where a detailed quotation is done, the source is always disclosed.

\section{Findings}

The findings of this study as presented below are reflections from my participant observation among the Nawfia of Southeastern Nigerian. This narrative is based on the accounts and experiences of the members of the society.

\section{Nawfia mortuary rites: common structures}

Among the Nawfia Igbo people, funeral ceremonies and burials are extremely complex, the most elaborate of all being the preparations for burial which aroused the researcher's interest. When someone dies, the relatives arrange and put the corpse in a morgue. Most of the time, the corpse would be in the mortuary as long as the preparations for the burial of the deceased last. In the case of wealthy people or moderately rich families, new houses are either built or the old ones renovated. Some even go to the extent of borrowing for the burial to be done. After the preparations, the date for the actual burial is announced through posters, radio or television. This is 
always done on a Thursday. Thereafter the interment and condolence continue up to Saturday. On Sunday the family of the deceased will be in church for thanksgiving service.

Nawfia mortuary rites vary with respect to the deceased's age, sex, social status and also the cause of death. Mortuary rites of a title man vary from that of a non-title man, women, youth, children or those who died of obnoxious diseases and whose death cannot be accounted for.

How we perform burial rites depends on whether the dead is young or old. We also look at it from whether the dead is a male or female or what they have accomplished, including the cause of the death. They all matter (male, 82 years).

In Nawfia the older a man or a woman is, the more descendants he or she is expected to have; the higher his or her rank and prestige, the more acceptable his or her death becomes. To die childless or without a son, is the most dreaded fate. Nawfia people believe that a person's survival is dependent on the performance of the appropriate mortuary rites for the person by the children. This is because failure to perform the mortuary rites will hinder the person's admission into the fold of his ancestors. Nawfia people believe that funeral rites are the most potent symbol of the parent/children relationship. This is why unmarried persons, childless men and women and children are usually accorded less elaborate mortuary rites. This implies that social differentiation which Nawfia people maintain in daily life is equally applied in the context of honour and respect given to the status of a dead member.

Mortuary rites are important for us. It is rooted in our culture and tradition. It is the only medium through which a dead member joyfully joins our ancestor. If 
you do not have children, who will bury you? It is the wish of every one of us to reach old age, take title, and have children... (Male, 85 years).

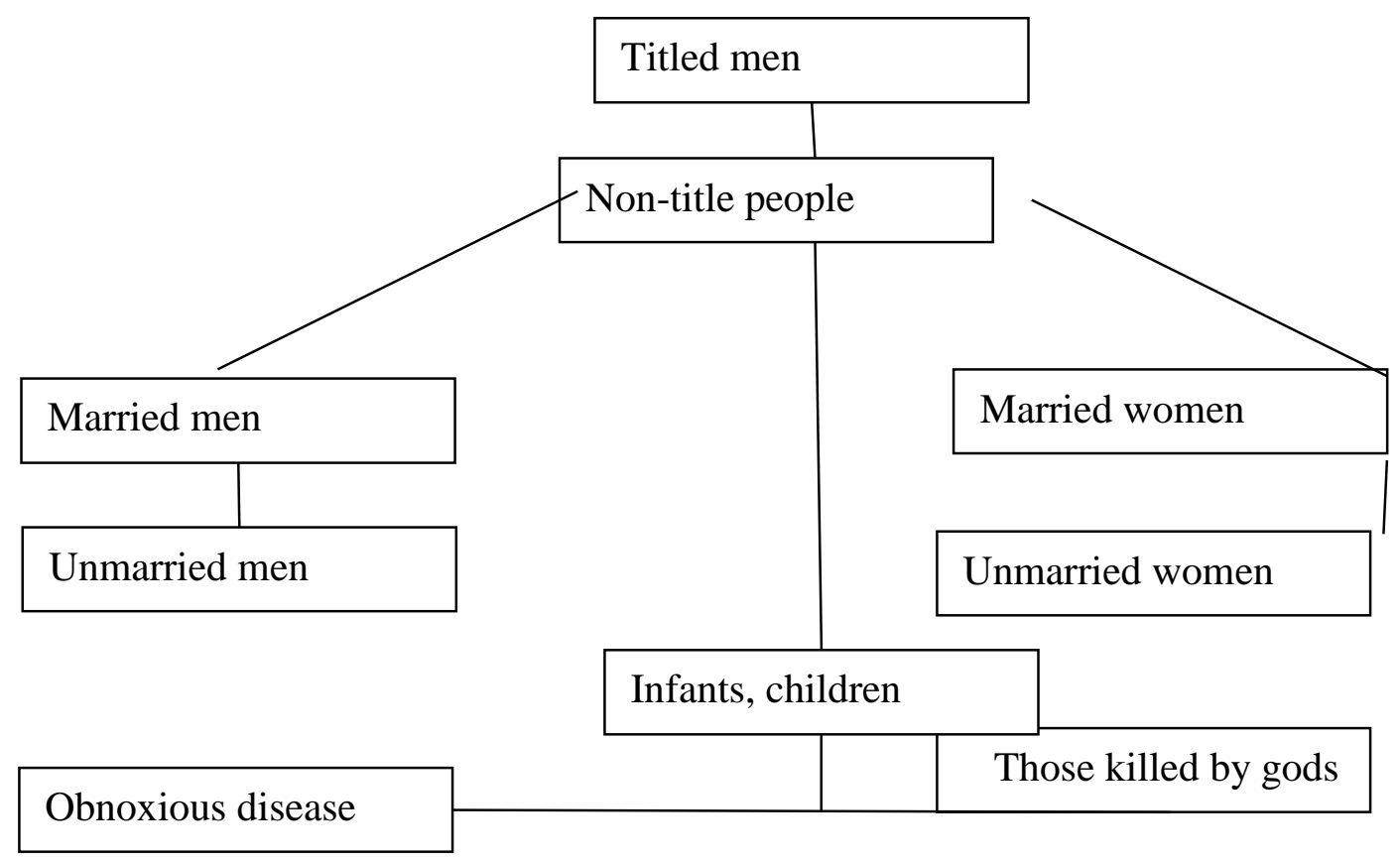

Figure 1. Gradation in Nawfia mortuary rites (drawn by Researcher) 
When death occurs, the deceased is not disposed of like the carcass of an animal. Certain rites accompany it. Nawfia people perform two categories of mortuary rites.

\section{First funerary rites}

The first funerary rites stage marks the time when the corpse is interred. That is, the processes involved in the interment of the remains of a dead person. It comes some hours, days or weeks after death depending on the status and requirements for the burial, and can be treated under the following headings.

1) Announcement of the death

2) Preparation of the corpse (ideziozu)

3) Preparation for burial (ikwadooliliozu)

4) Interment (ideweozu)

5) Mourning (irunkpe)

Death is always followed by wailing (ikuota, igbuemeri) of the household. It is from this wailing that the neighbours hear the news. Then a message will be sent to the relatives of the deceased to notify them of the death.

Before the preparation of the corpse for burial, it is assumed that the corpse must have been preserved as the time of burial lasts. The corpse is preserved by spreading castor oil leaves (akwukwuugba) on the ground where the corpse is laid. Dried snuff leaves (abubautaba) are stuck in the nostrils and in the anus of the corpse to prevent internal liquid content from flowing out. Then a seed of white melon (ahu-cucumeropsismannii) is put in the mouth and closed. The corpse is therefore cleansed periodically with dry gin. This can keep the corpse for a relatively long period of time without smelling or decaying. 
The preparation of the corpse is done by the married female relatives of the deceased (итиокри/uтиаda). There are two stages in the preparation of the corpse: bathing the corpse (iwuozuaru) and dressing of the corpse (iyibeozuakwa). Two umuada perform this task in the case of a titled man. In the case of non-titled persons, the nwaishiada (oldest daughter) performs this task. Water is poured on the roof of the deceased's house and a $n w o k u$ (clay pot) is used to collect it. The two umuada, stand by the side of the corpse facing each other. One of them holds the nwoku allowing others to dip her hands into the $n w o k u$, touching the water. She moves her hands in space from the head of the corpse down to the legs four times saying a wuo $m$ yaaru (I bath him) without touching the corpse, then touches her waste and then collects the $n w o k u$ from the other woman who then repeats the same thing. But in the case of a non-titled man the nwaishiadaalone performs this task.

After the corpse has been washed in the manner described above, it is finally clothed in its finest attire and set up in-state on uteamiri (a mat). In the case of a titled man, ugbeneichioku(a parrot's feather) and abubaugo (an eagle's feather), are stuck in the corpse's hair, then $n z u$ (native white chalk) is rubbed round its eyes (ibanzun'anya) which implies that the sight is at work even in death. Ufie (yellow chalk) is rubbed on the rest of the corpse. Relatives are then allowed to come and pay their last respect. This is not limited to the relatives only; well-wishers, friends, age grade groups of the deceased, in-laws are all involved. This is done in combination with ikpuakwa (clothing the corpse) a practice meant to provide the deceased with clothes to use in the spirit world. The act of preparing the corpse which includes bathing and dressing of the corpse, is anchored on the belief that a person who is travelling needs not be dirty so as to be welcomed by those he/she visits. 
Before burial, the corpse must be prepared in a special way. In traditional Nawfia burials, the coffin was not used. The corpse's two feet are tied together. The body is covered with ogodo(a wrapper [loin cloth]), usually a white piece of cloth and the corpse is placed on a mat (uteamiri). The uteamiri is used in combination with igugu (palm fronds). Also, in later traditional Nawfia burial, planks were used to make caskets. This is done inside the grave without nail counterforce in joining the planks. Woods are used in joining the planks inside the grave. A white cloth is placed on top of the corpse to cover it and the corpse is then carried by the deceased's clan members to the grave site. Exit from the house is always through the main door.

We prepare corpses before we bury them. It is sometimes seen as the last respect. We do not just bury the dead. They are prepared for the journey into the land of ancestors. Their acceptance depends on how they appear (female, 89 years).

Interment can be in the deceased's compound, in a distant place, in the forest, or in the bad bush (ojala), ugwuezu, etc as the case may be. Burial is always done in the evening or in the morning before sunrise except for children whose corpses can be interred at any time of the day. The third day of the native week afo is normally sacred as no burial holds on this day. This might be because the native market day of the Nawfia people holds on every afo market day.

The choice of the place to bury someone depends on who the person is, whether male or female, and the cause of death. Also, whether the dead is young or adult, married or unmarried is central to choosing where to bury those (male, 71 years). 
The digging of the grave (ijaili) is done by able-bodied men who may or may not come from the deceased's lineage but must be from the particular village of the deceased. Two iroko branches are placed, each on the side of the grave floor, to wedge the corpse when it is lowered into the grave. With the help of the able-bodied men the corpse, by means of ropes..., is lowered into the grave, in between the two iroko branches. Then the corpse is untied. The deceased's clothes, shoes, cap, etc., are all put into the grave. There is this belief that the deceased would need those items in the spirit world.

Before the grave is filled up, the first son of the deceased's children throws some earth into the grave. If it is a case of a man who has no son, one of the kinsmen throws earth into the grave. As the grave is about to be filled, nkpon'ala (cannons) are fired followed by outburst of wailing, especially by the females although this feeling is not hidden when one looks at the faces of the men. At the end of the interment, the family of the deceased presents food, drinks and kola nuts for everyone as a gift of appreciation for coming.

Mourning is the next rite that follows. In Nawfia, the umunna (clan) of the deceased usually mourn the deceased for twelve days (izuato) while the families of the deceased usually mourn for twenty-eight days (izuasaa). Before the burial, there is always the provision of mourning cloths which the family of the deceased will wear on the burial day. This cloth is to be worn for one year according to Nawfia traditional burial protocols. At the end of the one year, the cloth is removed and burnt together. The cloth is akwauju/akwamkpe. In the traditional Nawfia, the colour is usually black. On that last day of izuato, there is always another outburst of wailing at the deceased person's compound and nkpon'ala is fired. This in the Nawfia belief system means that the 
person is actually dead as no one can sleep for twelve days without getting up from sleep.

After the dead have been buried, we enter mourning. This time is a period of reflection. The immediate family lineage will stay at home without going to farm for twenty-eight days; this is called izuasaa. The members of the deceased clan will stay for twelve days, also known as izuato (male, 88 years).

\section{Second funeral rites}

Death ceremony comes to a climax during the second funeral celebration. This follows the interval of one year from the date of first funerary rites in traditional Nawfia society. In later developments, the time interval became dependent on the wealth of the bereaved family. The deceased has already been buried amidst much lamentation but with little ceremony. The second funerary rites normally come after igbukpoewu (ritual killing of the goat on the behalf of the deceased) in the case of married dead members of the society. The igbukpoewuis done at the confirmation of the death, that is, on the izuatocelebration. The igbukpoewuis done to pacify the dead person's spirit.

Until the funeral ceremony is observed, the dead continue to haunt this world, wandering at will in the household. The spirit of the dead is until the second funeral rites regarded as harmful and negatively influence the members of the family. He/she cannot enter the society of his/her dead kin and associates. Funeral ceremony obtains for the deceased, the certificate of entry into the home of his/her ancestors. In Nawfia, funeral rites are observed for all people but with variation.

Second funeral rite, known as $i k w a o z u$, is very very important in our custom. We believe that the spirit 
of the dead moves up and down. And they may hurt the living except if a proper funeral ceremony is performed. This traditionally is performed at oneyear interval after burial... and there are many rituals done in preparation to it (male, 84 years)

\section{Discussion}

All societies experience a certain amount of change in their social structure and culture over time. The culture of the Nawfia is not a static construction in time and space; it is rather in constant change. Among the factors of social change, Christianity made the most revolutionary impact on the socio-cultural life of Nawfia people. The missionaries established both churches and schools. It is mainly through the churches and schools that the Christian beliefs/doctrines were taught to the people.

This advent of Christianity cracked the whole fabric of the people's belief system. Christianity emphasizes belief in one God. This is not contradictory with the traditional religious belief; but the missionaries failed to understand that the ancestors who are venerated in traditional religion only serve as intermediaries between God who happens to be far away and the living person. Thus, the non-converts were termed pagans who worshiped idols.

Christians do not believe in reincarnation of the soul. They usually quote the Holy Bible that it is appointed unto man to die once and after death comes judgment, although an Eckankar[2] burial the researcher witnessed at Mmimi presented death as a translation from one body to another, or the translation of soul from physical body to spiritual body.

Unlike the traditional religious adherents who believe that when elders and titled men die, they join the world of the ancestors according to certain criteria, Christianity teaches that the soul of the 
dead goes to heaven or to hell irrespective of age or rank of the deceased. Going to heaven or to hell only depends on whether one lived according to the prescriptions of the Holy Bible while on earth. As a result of these beliefs, Christians accord the same burial rites to everybody whether married or unmarried, young or old etc.

Before the burial of a Christian,[3] a requiem mass is said (ikarayauka) for him/her by the priest/pastor and the church members in the deceased compound. The priest also prays at the grave before it is covered. Instead of having the deceased relatives carry the corpse to the grave, the church members do so. Eckankar burial is an exception to this. A priest is not around for anything, at the graveside when the deceased is being interred. The Eckankar members will do their songs of praise, followed by the Eckankar memorial service. Thereafter the Eckankar priest would announce to the relatives that the Eckankar people have finished their own part and that the kinsmen should go and bury their corpse. Christian religious faith has brought new rites, and obligations and the social status of a Christian as have earlier been remarked does not determine the kind of burial accorded to him/her.

Funerary rites in Nawfia today have undergone certain fundamental changes in the mourning obligation of widows and widowers which has been reduced to six months in the case of Anglicans and Catholics mainly and in the case of some Pentecostal churches to three months. Some of the Pentecostals do not even observe the obligations. Also, the ritual of hair cutting that marks entry into mourning (ajadu) in the case of a widow is no longer kept by most of the Christians. Furthermore, widows are no longer prohibited from entering the markets as churches confirmed that as being wrong. The mourning attire (akwankpe) is now white as opposed to black, which signified a bad moment or moment of grief on the body of those who wore them. The family mourning cloths 
also have been ridiculed to something of a model as they are no longer burnt by the end of the mourning.

Another noticeable change is that of imankpukpu (to build shades in the compound of the dead person with palm fronds). In the traditional Nawfia society, when a person dies and the date of the burial is fixed, relatives and villagers will assemble on the eve of the burial to build this palm frond shade in the compound. This is left up to the twenty-eighth days after the burial (izuasa) when it would be dismantled. Ima nkpukpu tells every Nawfia person that passed such that somebody died there. But recently, this has been replaced by modern canopies. This might be as a result of technological development.

Also, gun shots which formed a kind of death announcement and burial announcement too have been altered. Some Christians do not allow cannons to be fired before and even throughout the funeral rites. Some burials which the researcher witnessed at Iridana, Uruejimofor and Uruoji villages, all at IfiteNawfia, there were no gunshots. Also, at Umukwa, the researcher witnessed a burial where no cannons were fired.

Furthermore, the corpses married females' (ozunwaada) who were taken to their father's house for burial. But now, the burial is at the husband's place with a brief stopover (igbaokpa) at the father's house. Female corpse in traditional Nawfia is buried at the gate side or in front of the compound but all of the female corpses' burial I witnessed were done inside the compound. This is because, in traditional Nawfia society, married women's corpses are returned to their maiden homes. For that reason, the corpse is to be buried at the gate side or in front of the compound. However, with reasonably remonstrated appeals by the offspring of the deceased women across time, a woman's corpse is now buried in her husband's compound, albeit, the same position. 
Another noticeable change is in the issue of the second funeral. In the Christians doctrine any form of second funeral after the day of the burial is a sin. For them to be free from the said sin, they perform both the first burial and the second funeral on the same day. So, the cow which is to be used for the second funeral is killed and served to the congregation after the burial.

Nowadays, the coffin is used for burial except for infants/children from the age of 0 to 5 years of age. This change could be attributed to technological advancement. The method of preserving corpses (igbasiozu) is no longer by that crude way of spraying gin and snuff. It is now by embalmment or by preservation in hospital morgues.

There is an increasing disbelief in ogbanje and many children today are given respectful burials without being maltreated on the suspicion of being an ogbanje. People who die of obnoxious diseases are now given burial/funeral rites. Corpses are no more thrown into the evil forest. This may be as a result of the health hazard they may constitute.

The most alarming change that has been noted in mortuary rites is in the expenses of related ceremonies. The expenses involved in Nawfia mortuary rites are so alarming. The expenses in modern burial in Nawfia makes one wonder if the burial ceremony is more important than the other "rites of passage." Large sums of money are now spent for obituary announcements in all facets of the mass media, not to mention the extravagant spending indulged in entertaining people and adding colour to the occasion. Thus, it seems as if the magnitude of expenditure indulged in for a burial is taking over from rank and age as the measure of a family's social status.

The modern trend in Nawfia mortuary rites is not towards a total change. Certain aspects have been altered, and some others 
tend to persist. Some people who claim to be Christians still practice/perform the traditional mortuary protocol for their dead relatives. In the burial of titled men in the Nawfia, the rituals that are usually performed before inhumation have not been affected by Christianity.

The emergence of Christianity in the Nawfia created what could be described as mortuary dualism. This is a situation of contradiction between the autochthonous and alien mortuary rites. They are neither sure of what they have, nor confidence in the new cultural embrace. They are cut between the alien and autochthonous mortuary practices. The dual burial rites created a lot of problems and social tensions.

\section{Conclusion}

Nawfia mortuary rites reflect the social differentiation which characterizes their daily life. Thus, the type of mortuary rites accorded to a deceased is dependent on age, sex, social position, and cause of the death. These mortuary rites should be seen in terms of their symbolic meanings which are mainly the functions they perform in the maintenance of the entire social structure.

Death has a specific meaning for the social consciousness; it is the object of a collective consciousness. This is because funerary ceremonies provide one of the most important occasions upon which community/members of a community meet to express their unity and to reaffirm the values upon which that unity is based. Frequent attendance at these ceremonies does more than breed familiarity with the deceased's family; it intensifies the awareness of belonging to the community.

Christianity, which made the most revolutionary impact on the socio-cultural life of Nawfia people, and the education, which it brought, has affected Nawfia mortuary rites. Nevertheless, a total 
change has not been effected, as some aspects of the autochthonous mortuary rites tend to persist. The emergence of Christianity in the Nawfia created dual burial rites in the society. This is connected with the fact that some people, who claim to be Christians, still practice/perform the traditional mortuary rites for their dead members.

Ugochukwu T. Ugwu, PhD

Department of Sociology and Anthropology

Nnamdi Azikiwe University, Awka

ut.ugwu@unizik.edu.ng 


\section{References}

Basden, G. (1983). Among the Ibos of Nigeria. NP: University Publishing Co.

Borgatta, E. and Borgatta, M. (1992). Concepts of death and dying: An anthropological perspective. Encyclopedia of Sociology, vol. 1, 413-418. New York: Macmillan Pub. Comp.

Chukwuelobe, M. C. (1998). Death and the question of ultimate reality and meaning in the thought of the Igbo of Nigeria and of M. Heidegger: A further contribution to Uram Igbo studies. Ultimate Reality and Meaning 21(1): 317.

Hertz, R. (1960). Death and the right hand. Translated by R. and C. Needham. New York: Free Press.

Huntinghton, R. and Metcalf, P. (1979). Celebration of death: The anthropology of mortuary ritual. Cambridge: Cambridge University Press.

Igbo, E. \&Anugwom, E. (2001). Social change and social problem: A Nigerian perspective. Nsukka: AP Express Publishing Company.

Ikwuemesi, C. K. \& Onwuegbuna, I. E. (2018) Creativity in calamity: Igbo funeral as interface of visuality and

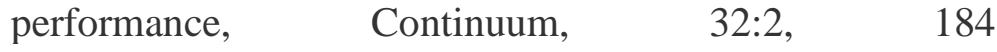
200, DOI: 10.1080/10304312.2017.1391176.

Ikwuemesi, C. K. (2021) Celebrating tragedy: dying, death and mortuary arts among the Igbo, Mortality, DOI: 10.1080/13576275.2021.1884 $\underline{057 .}$

Kottak, C. (2008). Anthropology: The exploration of human diversity. New York: McGraw- Hill Companies, Inc. 
Menkiti, I. A. (n.d.) Person and community In African traditional thought. Retrieved on $6^{\text {th }} \quad$ May 6, 2021, from https://scholar.google.com.

Nwanunobi, C., Chukwuezi, B., \&Onu, A. (2004). Introduction to Anthropology: Enugu: Ebenezer Production Nigeria Limited.

Obiechina, C.C. (1988) The Missionary Impact on Igbo Traditional Culture. University of Nigeria Research Publications. Retrieved on $6^{\text {th }}$ May 6, 2021, from https://scholar.google.com.

Ogbuagu, Stella C. "The Changing Perception of Death and Burial: A Look at the Nigerian Obituaries." Anthropologica, vol. 31, no. $1, \quad 1989, \quad$ pp. 85-101. JSTOR, www.jstor.org/stable/25605530. Accessed 6 May 2021.

Okpoko, P. and Ezeh, P. (2011). Methods in qualitative research. Nsukka: Great AP Express Publishers Limited.

Riley, J. (1968). Death: death and bereavement. InternationalEncyclopedia of Social Sciences.vol.3and4, pp. 303-306.

Talbot, P. (1969). Peoples of southern Nigeria. London: Frank Cass and Company Limited.

Van Gennep, A. (1960). The rite of passage. Translated by Monika, B. Vizedom and Gabrielle L. Caffee. London: Routledge and Kegan Paul.

Wilford, J. (2004). With escorts to the afterlife, Pharaohs proved their power. New York Times News Brief, March 16, pp. 2.

[1]In African religion: evil magic or charm.

[2]A confessional, sectarian entity, with Christian undertones.

[3]Roman Catholic. 